\title{
Competition, Innovation and Increasing Returns
}

\author{
Richardson, George B.
}

Document Version

Final published version

Publication date:

1996

\section{License \\ CC BY-NC-ND}

Citation for published version (APA):

Richardson, G. B. (1996). Competition, Innovation and Increasing Returns. DRUID - Danish Research Unit for Industrial Dynamics. DRUID Working Paper No. 96-10

Link to publication in CBS Research Portal

\section{General rights}

Copyright and moral rights for the publications made accessible in the public portal are retained by the authors and/or other copyright owners and it is a condition of accessing publications that users recognise and abide by the legal requirements associated with these rights.

Take down policy

If you believe that this document breaches copyright please contact us (research.lib@cbs.dk) providing details, and we will remove access to the work immediately and investigate your claim. 


\section{$\mathbf{D}_{\text {ANISH }} \mathbf{R}_{\text {ESEARCh }} \mathbf{U}_{\text {NIT FoR }} \mathbf{I}_{\text {NDUSTRIaL }} \mathbf{D}_{\text {YNAMICS }}$}

DRUID WORKING PAPER NO. 96-10

\section{Competition, Innovation and Increasing Returns}

by

George B. Richardson

July 1996 


\title{
Competition, Innovation and Increasing Returns
}

\author{
by \\ George B. Richardson \\ 33 Belsyre Court, Observatory Street \\ Oxford OX2 6HU \\ Phone/fax (01865) 510113
}

\begin{abstract}
This paper concerns the operation of competition in the presence of a high rate of innovation and increasing returns. Given free competition there is likely to exist, in this case, a tendency towards what may be called 'dynamic equilibrium', a tendency, that is to say, for the rate of investment in product development to rise or fall towards the level at which this investment yields only a normal return. Thus, competition, increasing returns and innovation may co-exist.
\end{abstract}

\section{Keywords}

Innovation, increasing returns, competition

\section{JEL classification}

D40, D20, D5, B1 


\section{Competition, Innovation and Increasing Returns}

I shall be concerned, in this article, with the way in which competition operates when there is a high rate of innovation and when production is subject to increasing returns. These two circumstances, as one might expect, are frequently found together; a high rate of innovation, as with pharmaceutical and software, frequently entails heavy costs of development or design, which are independent of the subsequent volume of output. These cases are important, and perhaps increasingly so; nevertheless, much of the analysis will apply also to industries where scale economies arise, not from high original or "set-up" costs, but from other factors.

No one can reasonably doubt the pervasiveness, in industry generally, of increasing returns. Adam Smith was certainly aware of it when he said that the division of labour is limited by the extent of the market, having observed that, where the scale of an economic activity increases, it will become practicable for component processes within it to be separated out. In general, the cost savings made available by an increase in the scale of a particular economic activity do not manifest themselves uniformly in all its stages and, as a result, an increase in demand may lead, not to an increase in the size of the enterprise undertaking the activity, nor to an increase in the number of such enterprises, but to a change in industrial structure, those stages exhibiting the greatest scale economies becoming the business of specialist suppliers. Smith went so far as to make the inter-relationship between the division of labour and the extent of the market the premise upon which to base what we would now call a theoryof self- sustaining economic growth, of growth associated with a continuous mutation in the structure of industry; increasing output both permitting, and being promoted by, the specialisation needed to realise scale economies.

It is worth observing that, for this reason, Smith's vision of the working of a market economy is quite profoundly different from that embodied in the formal models, based on universally decreasing returns to scale, that may appear to be in the line of descent. Economists, since the neo-classical development of their subject, have been inclined to regard the phenomenon of increasing returns, whatever its importance in practice, as analytically inconvenient. They saw that, if perfect competition were to be preserved, each firm must experience rising marginal costs while its output is still small relative to that of the whole industry. And, for it to be making a profit, marginal cost must be not less than average cost. Given these conditions, average cost cannot be falling with output, or, in other words, increasing returns cannot obtain.

It appeared, therefore, that if the growth of the firm was not to be checked by rising costs, it had to be checked by falling demand. A firm enjoying increasing returns could be in equilibrium, that is to say, only if it were faced by a sloping demand curve, with marginal revenue less than price. 
Only by sacrificing the assumption of perfect competition was it possible, it seemed, for a firm experiencing increasing returns to be in profitable equilibrium.

In this connection, John Hicks famously expressed the view that " a general abandonment of the assumption of perfect competition...must have very destructive consequences for economic theory". He thought it "only possible to save something from this wreck - and it must be remembered that the threatened wreckage is that of the greater part of general equilibrium theory - if we an assume that the markets confronting most of the firms with which we shall be dealing do not differ very greatly from perfectly competitive markets" ${ }^{1}$. This was the course which he himself followed, and most economists, implicitly or explicitly, have done likewise.

Chamberlin chose another path, ensuring the compatibility of competition and increasing returns by allowing each firm to have a monopoly of its own product, that product however being in competition with close substitutes. He then proceeded to show that firms in this situation, given sufficient pressure from the closely competing substitutes, would, in equilibrium, earn only the normal level of profits associated with competitive markets, the difference being that price would be equal to unit cost while unit cost was still falling with output ${ }^{2}$.

Chamberlin certainly provided us with an account of competitive markets more realistic than that offered by the theory of perfect competition. It was, however, more in harmony with an earlier tradition. The differentiation of activity it postulates is none other than a division of labour as practised among firms, the scope for which, according to Smith, was limited only by the extent of the market. In this respect Chamberlin's model differs radically from that of perfect competition, which, by requiring many firms to be engaged on identical activities, is in effect a denial of Smith's principle. But although Chamberlin allies himself with Smith in this respect, yet he places himself within the neo-classical tradition by virtue of his commitment to traditional equilibrium analysis. So long as we focus upon the properties of static equilibria, product differentiation is required if competition is to be compatible with increasing returns. I shall hope to show that, if we consider instead the processes of chang themselves, it becomes apparent that there are other circumstances able to ensure this result.

In the competitive equilbrium envisaged in models of both perfect and monopolistic competition, the marginal revenue from the sale of a product is equal the marginal cost of its production, and its price is equal to average cost. In the perfect competition equilibrium, average cost is at a minimum, whereas in monopolistic competition it is above this level. In both cases, rates of

1 J.R. Hicks, Value and Capital, Clarendon Press, Second Edition 1946.

2 E. H. Chamberlin, The Theory of Monopolistic Competition, Eight Edition, Harvard University Press, 1962 
output are being equated to rates of demand, on the assumption that both will be maintained indefinitely.

That this steady state assumption is highly unrealistic need hardly be said. Many, if not most products are launched in the expectation that they will have a limited life, either because they are superseded by a superior products, or simply because they go out of fashion. Durable goods, in particular, may be expected to have a particular pattern of sale, first rising as the demand for them builds up, and then, at best, falling to replacement level only. A software developer, for example, will certainly not think in terms of adjusting the rate of sales of a product to some hypothetical, constant and continuing rate of demand. He will think instead of the total quantity of sales that can be achieved before a new, superior product comes to dislodge his own; indeed, he may be already planning to bring out such a product, in order to forestall others from doing so. There will be no place in his thinking for cost and demand curves of the kind featuring in the models of competition we have been considering.

It is necessary to recognise the analytical limitations of demand and costs curves as we normally employ them. Implicit in their use is the assumption that the demand and cost conditions which they graphically represent are independent of each other, which is the case, however, only so long as the steady state is assumed, only so long, that is to say, as the postulated rates of demand can be assumed to persist indefinitely. On this assumption, the depreciation allowances that enter into costs will depend only on the physical life of the fixed equipment - although even here realism would make this itself dependent on rates of utilisation. Once we allow the demand for a good to be limited in time, depreciation allowances may depend, not on the physical durability of fixed equipment, but on the period for which it will be required. The average cost of the product will, where this is so, will depend on the total sales realised during its life time.

These circumstances lead us to envisage the co-existence of increasing returns with competition of a rather special kind. This may be made more readily apparent if we imagine a rather extreme and improbable situation in which one seller gains a total, but temporary, monopoly of a product. In the absence of any close substitutes, it might at first appear that the supplier would be able to earn a super-normal, monopoly profit. But this need not be so, as it is possible for a new product to come to replace the established one after an interval sufficiently short to permit the latter to yield only a normal profit. The price of the product would then, in the event, equal its average cost, in that total sales revenue equalled total costs incurred; if we wish to imagine this outcome to have been foreseeable, we can think of the fixed costs of the product being written off through depreciation allowances that are based on a correct estimate of the duration of the demand for it. 
We should not think, moreover, that such an outcome could occur only by chance. If we assume free competition, this would be the outcome generally to be expected. Investment in the industry, in freely competitive conditions, should tend towards the level at which, on average, products earned only normal profits, allowing for risk. But we have to think of the tendency to normal profits as arising, in the case we are considering, not through competitive investment which increases the supply of a product to match demand for it, but through competitive investment which displaces the existing product by an improved one. We have to think of investment, not in productive capacity, but in product development. For an entrepreneur engaged in the activities needed to identify, develop and test a product able to displace the incumbent one, his expectation of profit will depend on how he perceives his chances of effecting this displacement, and on how long he believes he can hold the position gained.

It is surely desirable for us to accept, in our formal theorising, that, in modern economies at least, by far the most important mode of competition is that based on development and innovation, whether in product or process. We concentrate too much, I believe, on monopoly revenue being obtained by the restriction of supply, and as threatened by entrants who might increase that supply. With that approach, it is natural for us to ask, for example, whether scale economies represent a barrier to entry, in that an entrant would have to produce, in order to achieve a competitive cost level, a volume of output which, if added to the industry's current output, would cause the market to be over-supplied. I do not doubt that considerations of this kind have some role to play, but it is much more common for firms to be challenged, not head on, but by those with something new to offer. It is for this reason, I suspect, that business men feel the world they live in to be much more competitive than economists appear to thnk it is, and for this reason that the industrial landscape can change so much in so short a time. David Audretsch $^{3}$ has shown just how great this change has been and how rapidly it appears to be accelerating. It took two decades for a third of the Fortune 500 to be replaced between 1950 and 1970, only one decade for a third to be replaced between 1970 and 1980 and only five years for a third to be replaced between 1980 and 1985. Equally striking has been the way in which a number of the most famous corporate giants, such as IBM, US Steel, RCA and Wang have lost, in his words, "their aura of invincibility", while new firms have emerged and risen to prominence.

I have chosen initially to postulate a highly unrealistic and limiting form of competition (which one might think of as sequential rather than concurrent), a form of competition which operates only through innovation, one particular product being assumed to obtain a total but temporary monopoly of its product class until a new product replaces it. Only by undertaking this replacement itself could the producing firm maintain its hold on the market, and even in these

3 Innovation and Industry Evolution by David B. Audretsch, MIT Press, 1995 
circumstances, the threat of competition, if strong enough, could oblige that firm to incur development expenses at a level which left it with only normal profits. I chose this case in order to show that competition, normal profits and increasing returns, could in this way all be compatible, even without assuming, as did Chamberlin, the simultaneous co-existence of a group of close substitutes. Chamberlin's competing monopolist occupies a niche in (economic) space, whereas we have been considering the possibility of occupying a niche in tim. Reality exhibits something of both modes of competition, but conforms to neither. And it is worth while examining why.

In the special case of purely "sequential" competition which I chose to consider, one product was imagined to enjoy a total monopoly in the market for its product class until displaced by another. This is, however, clearly unrealistic in that, although a new product may be superior to an old one in all respects, the process of replacement would very rarely be immediate. We cannot legitimately proceed from the assumption that the new product is uniformly superior, to the conclusion that it will be straight away, and by everyone, so perceived. Only too often analytical confusion results from implicitly assuming that what the model builder postulates to be objectively the case, is believed to be the case by the economic agents within the model. What these agents do will depend on their subjective perceptions of reality, and, where a new product is concerned, its properties will generally become manifest only after time and trial.

The marketing of a new product will therefore take time, and, of course, money. As demand for it builds up, productive capacity will have to be enlarged. Computer software presents an interesting and limiting case in which the sales that can be realised (in this case of licenses ) are not subject to this capacity limitation, which is one reason, but not the only reason, why software products can sometimes very rapidly gain or lose market share. In general, however, manufactured products will gain market share only gradually, as their merits become apparent and as the capacity to produce them is built up. During this period, rival offerings will still be on the market, and their life may be prolonged somewhat by price reductions that go some way to offset their disadvantages. Meanwhile, a new product, ready to challenge the one gaining ground, will be under development.

For these reasons, and despite increasing returns, one would expect several products to be selling at the same time, and not merely because differentiation gave to each of them its own group of loyal consumers. A plurality of products could remain in competition, even if they were objectively homogeneous. The configuration obtaining would not however be an equilibrium of the kind associated with Chamberlin's monopolistic competition. In that model, as in the perfectly competitive one, several producers will continue to compete in the market place, so long as demand and cost conditions do not change. In the case that I have been discussing, a plurality of producers obtains precisely because these conditions are in constant flux. 
Given free competition there is likely to exist, in this case, a tendency towards what we may call a dynamic equilibrium, a tendency, that is to say, for the rate of investment in product development to rise or fall towards the level at which this investment yields only a normal return. The qualification dynamic may serve to remind us that, in the situation we are describing, competition causes the profits of firms within an industry to tend towards a normal level, albeit with a great dispersion about the mean, not by the usual adaptation of supply to demand, but through variations in the rate of innovative activity.

Dynamic equilibrium, for the reasons I have given, is consistent with the co-existence of a number of competing firms, all of them supplying, in conditions of increasing return, products for the same general market. In reality of course, a market typically supports several firms because they are differentiated as well as because of what, for want of a better term, we might call the life-cycle effect that results from continuous development. One should not imagine that the co-existence of several firms, when it depends on the latter effect, and does not therefore constitute static equilibrium of the kind associated with the theories of either perfect or monopolistic competition, is for that reason somehow necessarily impermanent. The conditions favouring this co-existence - scope for innovation, uncertainty as to the properties of new products, the time taken to market a product and to build up the capacity to produce it - are unlikely themselves to be transitory.

The perfect competition model, it has frequently been observed, offers a paradox, in that it represents markets as tending towards a condition, the static equilibrium condition, from which the very activities which, in ordinary usage, represent competition are necessarily absent. In equilibrium, producers, as well as consumers, are mere price takers, unable, ex hypothesi, to improve their existing products or offer new ones. Competition is seen as reaching its apotheosis, one might almost say, when it all but ceases to exist. The maintenance of a plurality of firms in dynamic equilibrium, by contrast, depends on continuously active competition in all its dimensions.

But might it not be argued that the simultaneous co-existence in this way of a number of competing, objectively homogeneous offerings, each produced under increasing returns, depends not on the intensity of competition, but on its imperfection ? Without imperfect knowledge, all demand would switch to the best product within the particular market, and without imperfect mobility of resources, the supply of that product would appropriately respond. There would exist only one producer of each product variety, as in the equilibrium associated with monopolistic competition.

On the face of it, this logic may seem convincing. If everyone always knew everything, and if processes were timeless, continuing competition of the kind I have described would indeed not 
exist, but neither of course would any economic order that we can possibly imagine. Any model based on the assumption that perfect knowledge and perfect resource mobility universally prevail is objectionable, not because it is obviously unrealistic, but because it would be impossible. An economy in which these conditions obtain obviously does not exist, and, less obviously, could not do so. Where the actions of economic agents are inter-dependent, it is illogical to assume that each one of them is free to do whatever he or she likes without constraint, while at the same time having perfect knowledge of what all the others will do $^{4}$.

We must now consider whether a state of dynamic equilibrium would require there to be imperfection of a different kind, imperfection in the sense of the restraint in price competition characteristic of oligopoly. It has, after all, long been accepted that several competing goods, each being produced under increasing returns, might co-exist on the market place provided the firms making them were to exercise this restraint. In the situation hypothesised, each producer assumes that his rivals would match any reduction in his price, thus denying him any increase in market share. His sales would therefore increase only in accordance with the elasticity of demand for the product as a whole, rather than the elasticity of demand for his particular offering, if measured on the assumption that the prices of the competing products remained unchanged. In these circumstances, producers might not reduce price; several firms would stay in business, despite the fact that they were each experiencing increasing returns.

Behaviour of this sort may be responsible for the survival of a number of competing firms each making the same product under increasing returns, but it is by no means a necessary condition. In any case, a firm has reasons not to avoid price reductions other than the likelihood that competitors will match them. It was noted that a firm bringing in a new product cannot expect its properties, or even its existence, to be known to everyone in the market; time will be needed to undertake effective marketing and to build up the needed reputation. And even if demand could be created instantaneously and without cost, the capacity required to meet it cannot normally be so created. In these circumstances, the firm will not expect too much from a price reduction, even if the suppliers of competing products do not retaliate. A price reduction will not be seen, in other words, as a short- cut to increasing sales, an alternative to a time consuming and expensive marketing effort. The possibility of a dynamic equilibrium, ith several suppliers in the market, does not depend on the kind of tacit collusion on prices associated with oligopoly.

It may be helpful, at this stage, to take stock of where the argument has reached. It is obvious, to all those who wish to see, that, in the real world, competition does co-exist with increasing returns to scale. Chamberlin's theory of monopolistic competition offered product differentiation

4 This matter is discussed at length in Part I of my book: Information and Investment, Clarendon Press, Oxford, 1990 
as providing one explanation; each firm enjoys a monopoly in the particular variety it puts on offer, but competition from close substitutes may establish a normal rate of profit. In equilibrium, unit costs are falling with output, but so is the level of demand; the demand curve, in other words, is tangential to the average cost curve.

I have suggested that there may be co-existence for a further, different reason. In industries where there is continuous development and innovation, - the difference between these, in this context, being one of degree - existing products are subject to displacement by new ones, the rate of investment in development tending, in competitive conditions, towards the level at which the life span of products is no longer than permits, on average, normal profits to be earned. The result of this process, typically, will be to leave several producers in the market, not only because they cater to different needs, but because it takes time for new products to gain ground and for old ones to be driven from the field.

In these circumstances, I believe that we are justified in talking in terms of a tendency towards a dynamic equilibrium. Product innovation generally requires investment, which will be undertaken in the hope of profit; in a regime of economic freedom, therefore, one should expect large and sustained divergences between the return on such investment to create signals and incentives which will cause them to be reduced. It goes without saying that, in real life conditions, this tendency will manifest itself in only a very approximate manner, but this is not to say that it will not manifest itself at all. Common observation shows, in a broad way, how free competition causes resources to flow in response to perceived profit opportunities, and there is no reason to regard investment in innovation or development as different in this regard from investment undertaken to increase the amount of different goods being supplied.

It may be objected, however, that the term equilibrium is misapplied to the state of affairs which I have sought to describe, in that it attributes stability to a state of constant flux. But for the use of this language, there is an illustrious precedent. The long -run equilibrium of an industry, as defined by Marshall, is consistent with the rise and decline of firms within it, hence his famous analogy with the trees of a forest and the use he made of the concept of the "representative firm" ${ }^{5}$. Dynamic equilibrium has obvious similarities to this state, but relates, not to the volume

5 Marshall, Alfred. Principles of Economics Book V, Chapter V. No one, it seems to me, had a better sense than did Marshall of the way in which equilibrium analysis in economics is made difficult by the element of time, and more awareness of the dangers run in this field by those who, in his language "follow their mathematics boldly". And, as has frequently been observed, his treatment anticipates a host of subsequent developments. I am inclined to think that both the importance of high, fixed, development costs and the rate of product development is faster now than when he wrote the Principles. Perhaps it is for this reason that he does not explicitly consider equilibrium in terms of the rate of investment in innovation, but perhaps it was because he thought, as he put it that "...such notions must be taken broadly. The attempt to make them precise over-reaches our strength." 
in which a product or group of products is supplied, but to the rate at which their development proceeds.

We have to accept, in fact, that there are different kinds and levels of equilibrium. The total supply of a product may, in Marshall's account, be in equilbrium with the demand for it, while the firms within the industry, which may be expanding or contracting, are not. Similarly, the rate of investment in innovation within an industry may be in equilibrium, in the sense that the prevailing expectation of profit provides no inducement to increase or reduce it, while the plans made by firms within the industry, in respect of both the nature and the quantities of the goods they make, are frequently being revised.

It might be said that the process of competition, as I have described it, is one of permanent disequilibrium, the natural tendency towards monopolisation of a market, which one would expect increasing returns to create, being continuously frustrated by the emergence of a new product. And if we are to regard innovation as essentially exogenous, such an account of the matter would be acceptable. I certainly do not wish to deny that it may frequently be appropriate to describe the evolution of industry in terms of reaction to random shocks. But there are surely many industries in which all firms recognise that they must continuously invest in product development in order to survive. In these industries, the displacement of existing products by new ones will not come as a surprise; the event will be consistent with the expectations held and in no way represent their disappointment. Professor Hahn has proposed a definition in saying that "an economy is in equilibrium when it generates messages that do not cause agents to change the theories which they hold or the policies which they pursue" ${ }^{6}$. And if one were to accept such a definition, then my use of the term, albeit in a special dynamic context, would seem to be justified. The coexistence of competition and increasing returns could be described as a disequilibrium phenomenon only within the framework of comparative statics. If further product development were somehow suddenly impossible, then Sraffa's logic would apply and this coexistence would break down. But this framework is surely inappropriate where uninterrupted product development is the normal, and universally expected, state of affairs. In that context, it seems to me that we should be concerned with the equilibrium rate of investment in development, with the tendency for the actual rate prevailing in a particular industry to vary so as to bring the expected financial yield into line with that prevailing generally ${ }^{7}$.

6 F. H. Hahn, On the Notion of Equilibrium in Economics, Cambridge University Press, 1973.

7 In order more fully to explain the course of industrial development, the process of innovation would need to be subject to closer analysis. A familiar distinction could be made between radical innovation, of which the microprocessor would be an example, and routine innovation of the kind that I have been discussing. The former can be regarded as desequilibriating, and may give rise to abnormally high profits, whereas the latter is undertaken, by most firms most of the time, in order to earn a normal profit. 
It may be argued that investment in product development may not create a tendency toward a normal rate of return, as I have suggested, for the reason that incumbent firms are better able successfully to undertake it. They will be familar with the relevant technology and their existing position in the market will make new offerings made by them more readily acceptable than those of outsiders. No doubt this is true, but such advantages are hardly the stuff of which anti-social monopolistic protection can for long be made. There is a good deal of historical experience to show that those who have become expert in doing something one way may well not be the first to observe that it could better be done some other way, and to show also that an established reputation may sap the energy and weaken the initiative of those who seek shelter behind it. We have to ask ourselves, moreover, whether any advantages of incumbency, any sluggishness is the process of competition, is to be deplored. It is certainly desirable tht control over resources should move to successful from unsuccessful firms, but we should not want the process of transfer to be more rapid than the natural mobility of resources can make efficiently possible. Some academic observers would seem to believe that inter-firm competition should approximate to some ancient gladiatorial display, the resultant carnage proving how well it works. Those within industry have a livelier sense of the genuine social losses associated with closure and redundancy, and not just because their jobs are at stake.

I have been concerned with the way in which competition operates where there are increasing returns to scale and a high rate of innovation. These conditions, of course, are not universal, and the analytical framework I have sketched out does not therefore universally apply. But we should not expect competition always to work in the same way, whether in the supply of computers or of cocoa beans. I mentioned, at the outset, pharmaceuticals and software, where competition most obviously takes the form I have described. In both industries, indeed, the investment called for is overwhelmingly in development, in which we should include expensive and time consuming testing procedures, and in marketing. There can be no question but that this investment, no less than investment in manufacturing capacity, is undertaken on the basis of expected financial return. The expectations will be highly uncertain and, in consequence, realised returns will show great variation. The spectacular returns earned from some software proucts come easily to mind, but it is well to remember also the many which have failed.

It may be questioned whether, given the great uncertainty associated with the return to investment in development, it makes sense to suppose that any equilibrium tendency is at work. No doubt there is wide variation in the realised profits from this investment, both within and between industries, but free competition is as likely in this activity, as in others, to prevent large differences persisting over time. Whatever the qualifications that we find it necessary to make, we accept that, in a regime of economic freedom, the pattern of output will accord, in some reasonable degree, with what people are prepared to pay, and the processes of production, in some reasonable degree, will make efficient use of the needed scarce resources. For the same 
reason, there is a presumption that, under the influence of the profit motive, the pattern of investment in product development will accord, if only approximately, with the value that consumers will place on different developments. And even the total value of such inestment activity will be influenced, if only very loosely, by how much consumers are prepared to pay for novelty.

The reader, lamenting the looseness of this argument, may look back, with longing, to the clarity and precision of formal models. He may recall, with sympathy, Sir John Hicks's view, referred to above, that a general abandonment of perfect competition must have very destructive consequences for economic theory. But, as I have endeavoured to show elsewhere, the claims of the perfect competition model are completely spurious, as its internal logic is fatally flawed. I hope ( and believe ) that the argument which I have sketched above can be developed more fully and with greater rigour, but, in the end, we may have to accept Aristotle's view that "Our discussion will be adequate if its degree of clarity fits the subject -matter, for we should not seek the same degree of exactness in all sorts of arguments alike"8.

8 Aristotle's Nicomachean Ethics, Book 1, Chapter 3, translated by Terence Irwin, Hackett Publishing Company, 1985. 


\section{$\mathbf{D}_{\text {anish }} \mathbf{R}_{\text {esearch }} \mathbf{U}_{\text {nit tor }} \mathbf{I}_{\text {ndustrial }} \mathbf{D}_{\text {ynamics }}$}

The Research Programme

The DRUID-research programme is organised in 3 different research themes :

- The firm as a learning organisation

- Competence building and inter-firm dynamics

- The learning economy and the competitiveness of systems of innovation

In each of the three areas there is one strategic theoretical and one central empirical and policy oriented orientation.

\section{Theme A: The firm as a learning organisation}

The theoretical perspective confronts and combines the ressource-based view (Penrose, 1959) with recent approaches where the focus is on learning and the dynamic capabilities of the firm (Dosi, Teece and Winter, 1992). The aim of this theoretical work is to develop an analytical understanding of the firm as a learning organisation.

The empirical and policy issues relate to the nexus technology, productivity, organisational change and human ressources. More insight in the dynamic interplay between these factors at the level of the firm is crucial to understand international differences in performance at the macro level in terms of economic growth and employment.

\section{Theme B: Competence building and inter-firm dynamics}

The theoretical perspective relates to the dynamics of the inter-firm division of labour and the formation of network relationships between firms. An attempt will be made to develop evolutionary models with Schumpeterian innovations as the motor driving a Marshallian evolution of the division of labour.

The empirical and policy issues relate the formation of knowledge-intensive regional and sectoral networks of firms to competitiveness and structural change. Data on the structure of production will be combined with indicators of knowledge and learning. IO-matrixes which include flows of knowledge and new technologies will be developed and supplemented by data from case-studies and questionnaires. 


\section{Theme C: The learning economy and the competitiveness of systems of innovation.}

The third theme aims at a stronger conceptual and theoretical base for new concepts such as 'systems of innovation' and 'the learning economy' and to link these concepts to the ecological dimension. The focus is on the interaction between institutional and technical change in a specified geographical space. An attempt will be made to synthesise theories of economic development emphasising the role of science based-sectors with those emphasising learning-by-producing and the growing knowledge-intensity of all economic activities.

The main empirical and policy issues are related to changes in the local dimensions of innovation and learning. What remains of the relative autonomy of national systems of innovation? Is there a tendency towards convergence or divergence in the specialisation in trade, production, innovation and in the knowledge base itself when we compare regions and nations?

\section{The Ph.D.-programme}

There are at present more than $10 \mathrm{Ph} . \mathrm{D}$.-students working in close connection to the DRUID research programme. DRUID organises regularly specific Ph.D-activities such as workshops, seminars and courses, often in a co-operation with other Danish or international institutes. Also important is the role of DRUID as an environment which stimulates the Ph.D.-students to become creative and effective. This involves several elements:

- access to the international network in the form of visiting fellows and visits at the sister institutions

- participation in research projects

- access to supervision of theses

- access to databases

Each year DRUID welcomes a limited number of foreign Ph.D.-students who wants to work on subjects and project close to the core of the DRUID-research programme.

\section{External projects}

DRUID-members are involved in projects with external support. One major project which covers several of the elements of the research programme is DISKO; a comparative analysis of the Danish Innovation System; and there are several projects involving international co-operation within EU's 4th Framework Programme. DRUID is open to host other projects as far as they fall within its research profile. Special attention is given to the communication of research results from such projects to a wide set of social actors and policy makers. 


\section{DRUID Working Papers}

96-1 Lundvall, Bengt-Åke: The Social Dimension of the Learning Economy. (ISBN 87-7873-000-7)

96-2 Foss, Nicolai J.: Firms, Incomplete Contracts and Organizational Learning. (ISBN 87-7873-001-5)

96-3 Dalum, Bent and Villumsen, Gert:Are OECD Export Specialisation Patterns 'Sticky?' Relations to the Convergence-Divergence Debate. (ISBN 87-7873-002-3)

96-4 Foss, Nicolai J: Austrian and Post-Marshallian Economics: The Bridging Work of George Richardson. (ISBN 87-7873-003-1)

96-5 Andersen, Esben S., Jensen, Anne K., Madsen, Lars and Jørgensen, Martin: The Nelson and Winter Models Revisited: Prototypes for Computer-Based Reconstruction of Schumpeterian Competition. (ISBN 87-7873-005-8)

96-6 Maskell, Peter: Learning in the village economy of Denmark. The role of institutions and policy in sustaining competitiveness. (ISBN 87-7873-006-6)

96-7 Foss, Nicolai J. \& Christensen, Jens Frøslev: A Process Approach to Corporate Coherence. (ISBN 87-7873-007-4)

96-8 Foss, Nicolai J.: Capabilities and the Theory of the Firm. (ISBN 87-7873-008-2)

96-9 Foss, Kirsten: A transaction cost perspective on the influence of standards on product development: Examples from the fruit and vegetable market. (ISBN 87-7873009-0)

96-10 Richardson, George B: Competition, Innovation and Increasing Returns. (ISBN 877873-010-4)

\section{Information for subscribers.}

Subscription price for 1996 is 600 DKR (about 20 papers). The rate for single issues is 40 DKR. It is possible to make a commitment to an exchange of papers from related departments or research teams. All correspondence concerning the DRUID Working Papers should be send to:

Mette Madsen

Fibigerstræde 4, DK-9220 Aalborg OE

Tel. 45981542 11-2945

Fax. 4598156013

E-mail: mm@business.auc.dk 